\title{
Comparison of three silane compounds to impart water repellency in an industrial sand
}

\author{
C. S. H. CHAN* and S. D. N. LOURENÇO*
}

\begin{abstract}
Water repellent granular materials have been tested in water harvesting applications and proposed as landfill and slope covers. To achieve water repellency, sand particles are coated with waxes, oils or silanes. This paper focuses on silanes because they are widely used in glass coating applications, and thus pertinent for use on silicate minerals for enabling a high degree of water repellency to be attained. Three silane compounds were tested on medium-sized sand: dichlorodimethylsilane (DCDMS), octadecyltrichlorosilane (OTS) and trimethylchlorosilane. The aim was (a) to identify the minimum concentrations required to achieve the highest degree of water repellency, $(b)$ to ensure its stability after treatment and $(c)$ to determine potential conditions or factors to enhance water repellency. The results revealed that only a small amount of silanes, $0.001 \%$ by soil mass, was required for the treated sands to reach the maximum degree of water repellency with OTS achieving the highest $\left(138^{\circ}\right)$ and DCDMS the lowest $\left(124^{\circ}\right)$. From the findings, it can be concluded that the combination of OTS treatment in air-dried clean sand provides the highest and most stable water repellent behaviour, paving the way for future research in cover applications where water tightness is of paramount importance.
\end{abstract}

KEYWORDS: geosynthetics; ground improvement; particle-scale behaviour; sands

ICE Publishing: all rights reserved

\section{INTRODUCTION}

Water repellent soils resist infiltration when the contact angles (CAs), a measure of water repellency, exceeds $90^{\circ}$. They were first identified in the natural environment where their occurrence hinders water infiltration and increases surface runoff (DeBano, 1981). In agricultural soils, they lead to water inefficiency (Roper, 2005) due to preferential flow (Jamison, 1946; Bond \& Harris, 1964; Gilmour, 1968) affecting plant growth (Dekker \& Ritsema, 1994; Doerr et al., 2006).

For the built environment, synthetic water repellent soils offer several benefits as construction and building materials. Being impermeable to water in its liquid form, they could act as hydraulic barriers to restrict infiltration of water (e.g. landfills or unstable slopes) while remaining volumetrically stable if coarse-grained materials are to be used - that is, with no shrinkage and desiccation cracks. However, their pore size and the magnitude of water repellency control the water-entry value suggesting that its use in ponding applications (e.g. flood defences) is restricted by the head of water.

To date, a variety of substances have been tested for their water repellent behaviour: natural substances, such as dissolved organic carbon (Lamparter et al., 2009), perfluorinated compounds and paraffin/wax, for textiles (Schuyten et al., 1948) and silanes for glass coatings (Tripp \& Hair, 1995). Silanes are among the most suitable as they induce high and stable water repellency and share a common chemistry (Bachmann et al., 2003). These have also

Manuscript received 28 June 2016; first decision 3 October 2016; accepted 4 October 2016.

Published online at www.geotechniqueletters.com on 26 October 2016.

*Department of Civil Engineering, The University of Hong Kong, Hong Kong, Hong Kong. been used for protective applications: protective and antirefractive optical coatings on glasses, anticorrosion coatings, scratch-resistant and anti-ageing coatings (Pagliaro et al., 2009; Zhou et al., 2015).

Silanisation is the process whereby silanes react with water and silica surfaces to form new polymers with water repellent properties (Fig. 1) (Mahltig \& Bottcher, 2003). The following silanes have been used in various applications: dichlorodimethylsilane $\left(\mathrm{CH}_{3}\right)_{2} \mathrm{SiCl}_{2}$ (DCDMS) (Ju et al., 2008), octadecyltrichlorosilane $\mathrm{CH}_{3}\left(\mathrm{CH}_{2}\right)_{17} \mathrm{SiCl}_{3}$ (OTS) (Byun et al., 2012) and trimethylchlorosilane $\left(\mathrm{CH}_{3}\right)_{3} \mathrm{SiCl}$ (TMCS) (Gao \& McCarthy, 2006). DCDMS, OTS and TMCS have different molecular structures and physical properties, but share a similar reaction mechanism with silica surfaces that depends on water content and the functional groups of the reactants (Gao \& McCarthy, 2006). Both DCDMS and OTS have been used in soils and their water repellency characteristics have been examined, but no information exists for TMCS.

This study will determine the differences between DCDMS, OTS and TMCS with the view of establishing the silane compound that develops the highest water repellency at the lowest concentration for cost benefit and ensuring its time stability. Building on previous research that revealed preference for clean soils for the treatment to induce water repellency $(\mathrm{Ng} \&$ Lourenço, 2016), clean, medium-sized sand is used [Leighton Buzzard sand (LBS)].

\section{MATERIALS AND METHODS \\ Sample preparation}

To induce water repellency, samples were air dried at room temperature; this was followed by weighing in a beaker and the required volume of DCDMS, OTS or TMCS (ACROS ORGANICS, Geel, Belgium), in a liquid form, added by means of a micropipette. OTS was stored at an ambient 


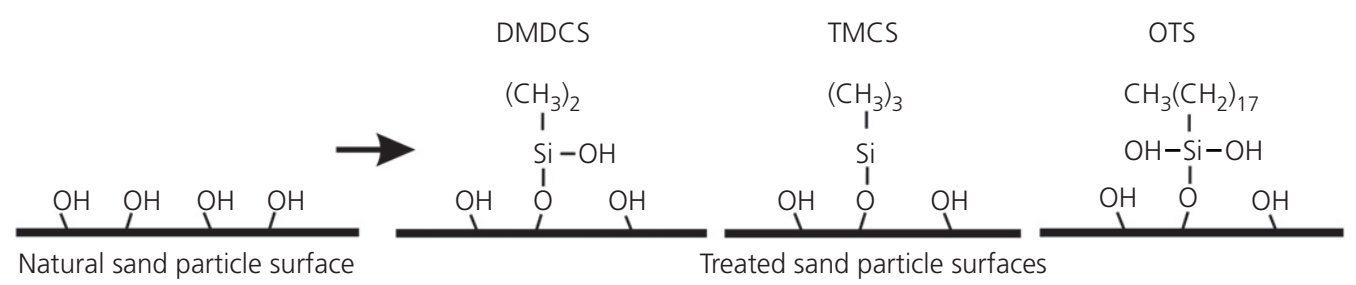

Fig. 1. Schematic view of silane formation on the surface of silica surfaces for DCDMS, TMCS and OTS; several arrangements are possible, shown is the monolayer formation

temperature $>20^{\circ} \mathrm{C}$ (melting point); DCDMS and TMCS have lower melting points (Table 1). As the micropipette is able to dispense liquids to an accuracy of only $\pm 1 \mu$, the mass of silane was fixed while the mass of soil was adjusted with the density of the silane accounted for (Table 1). To avoid exposure with hydrogen chloride fumes that is a by-product of the reaction, the silane was added to the sand sample in a fume cupboard and gently stirred for $30 \mathrm{~s}$ with a glass rod. In order to ensure complete reaction as the residual silanes react with water vapour, the samples were left exposed to the ambient air for $24 \mathrm{~h}$ prior to any water repellency assessment.

For the effect of liquid water in the sand, samples were prepared with increasing water contents. The sand samples were initially dried at $105^{\circ} \mathrm{C}$ for $24 \mathrm{~h}$, allowed to cool, weighted and a predetermined volume of water added to the sand, followed by a volume of silane. The data was presented as a water to silane ratio, where a ratio of 1 implies that an equivalent amount of water and silane were added to the sand sample. Given its higher water content, a minimum of 3 days was allowed for the reaction to end before measuring water repellency.

These procedures were implemented for the DCDMS, OTS and TMCS separately. The testing programme was initiated for the air-dried samples with DCDMS, as both have been tested previously; testing was then done on the samples with higher water contents for OTS and TMCS.

\section{Water repellency measurement}

The stability or persistence of water repellency was assessed by the water drop penetration time test (WDPT). The WDPT is the time for a water drop of $80 \mu \mathrm{l}$ to infiltrate into the soil. Water repellency is classified according to a rating class system that ranges from wettable (class 0 with the water drop infiltration in $<5 \mathrm{~s}$ ) to extreme water repellency (class 10 with the water drop infiltration $>5$ h) (Doerr et al., 2006). For water drops remaining on the surface of the soil for a time period of $5 \mathrm{~h}$ or more, WDPT is terminated since evaporation will affect the test results.

The magnitude of the soil water repellency was determined by means of CA measurements using the sessile drop method (SDM). Higher CA implies higher water repellency. In this study, the Drop Shape Analyser 25 (DSA) (KRÜSS, Hamburg, Germany) was used for CA measurements (Fig. 2). The sample preparation procedure for the SDM first consisted of gluing a double-sided tape on one side of a microscope slide. The sand was gently sprinkled on the

Table 1. Properties of the silanes (data ACROS ORGANICS)

\begin{tabular}{|c|c|c|}
\hline Compounds & Density: $\mathrm{g} / \mathrm{ml}$ & Melting point: ${ }^{\circ} \mathrm{C}$ \\
\hline $\begin{array}{l}\text { DCDMS }\left(\mathrm{CH}_{3}\right)_{2} \mathrm{SiCl}_{2} \\
\mathrm{OTS} \mathrm{CH}{ }_{3}\left(\mathrm{CH}_{2}\right)_{17} \mathrm{SiCl}_{3} \\
\text { TMCS }\left(\mathrm{CH}_{3}\right)_{3} \mathrm{SiCl}\end{array}$ & $\begin{array}{l}1 \cdot 07 \\
0 \cdot 98 \\
0 \cdot 85\end{array}$ & $\begin{array}{r}-76 \\
20 \\
-77\end{array}$ \\
\hline
\end{tabular}
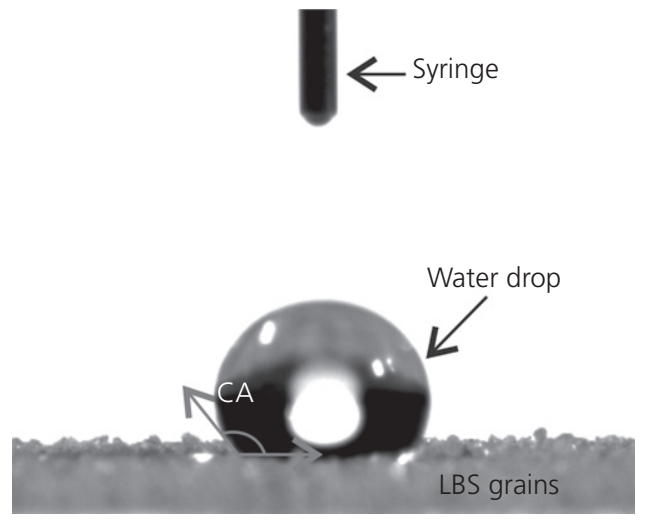

Fig. 2. CA measurement with the SDM (water drop diameter $\sim 6 \mathrm{~mm})$

surface of the tape and gently shaken to remove the excess material. This was then followed by applying a $1 \mathrm{~N}$ force on the slide. The procedure was repeated twice. The glass slide was then placed on the stage of the DSA and a volume of $10 \mu \mathrm{l}$ added to the surface by means of an automated syringe. The evolution of the air-water interface of the drop was recorded by means of a charge coupled device camera with a resolution of 82 frames per second and the CA determined by using a curve-fitting algorithm based on Young-Laplace equation applied to the first recorded images, typically within the first $50 \mathrm{~ms}$ to minimise gravity and roughness effects (Bachmann et al., 2003). In order to limit the large standard deviations associated with $\mathrm{CA}$ measurements, a minimum of ten readings were recorded for each sample.

\section{RESULTS AND DISCUSSION}

\section{Water repellency and its stability}

LBS treated with the three silanes achieved high water repellency at relatively low percentages by sand mass of silane (Fig. 3). Untreated LBS CAs were $\sim 30^{\circ}$. After treatment, the maximum CA reached by OTS, TMCS and DCDMS were $138^{\circ}, 131^{\circ}$ and $124^{\circ}$, respectively, at a concentration of $0.004 \%$ by sand mass of silane. Further increase in silane concentrations did not cause any increase in CA. Standard deviation for the CAs ranged between $\pm 1^{\circ}$ and $\pm 4^{\circ}$. For the WDPT, OTS achieved the highest stability at the lowest concentration (class 10 at $0.001 \%$ by sand mass of silane) (Fig. 4). This was followed by class ratings of 9 and 8 for DCDMS and TMCS, respectively, at $0.0015 \%$ by sand mass of silane. The three silanes achieved the maximum class (10 - extreme water repellency) with $0 \cdot 004 \%$ by sand mass of silane.

Both sets of results are in agreement, with the OTS providing the highest and most stable CAs from the lowest percentages by sand mass of silane. As for the opposite response from DCDMS and TMCS, while the difference 


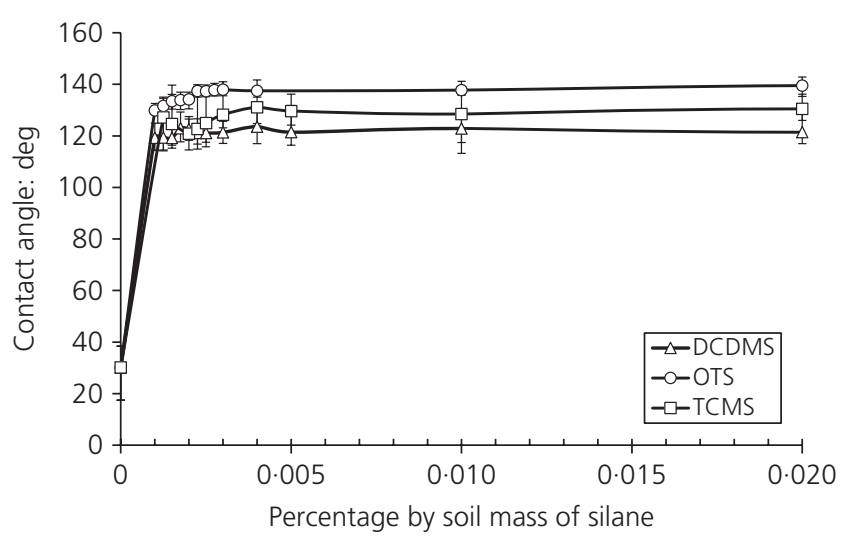

Fig. 3. CAs for TMCS, DCDMS and OTS on LBS

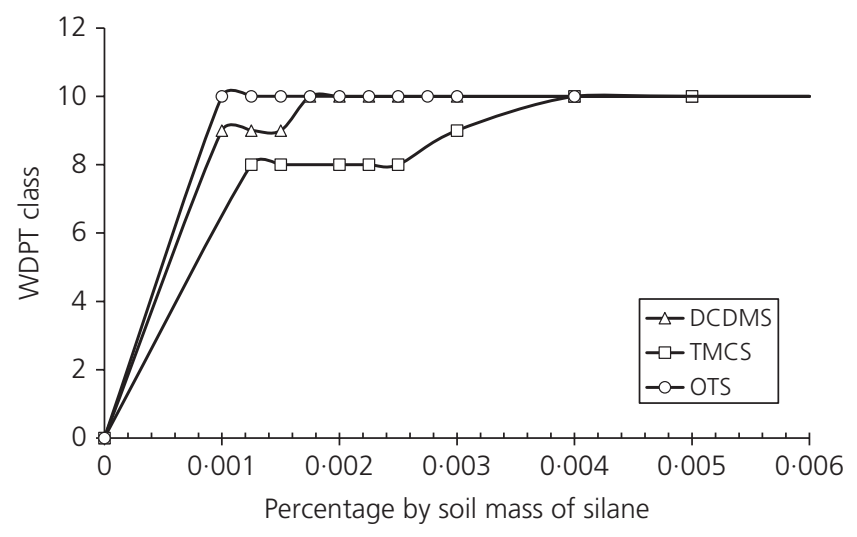

Fig. 4. Time stability for TMCS, DCDMS and OTS on LBS

between the CAs is small at $\sim 8^{\circ}$ and unlikely to alter the wetting behaviour of the treated soil, the difference in the WDPT between class 8 and 10 is significant. Class 8 corresponds to $15 \mathrm{~min}$ infiltration time whereas the DCDMS class 10 corresponds to $>5 \mathrm{~h}$. CAs do not necessarily correlate with the WDPT. Therefore, DCDMS would be favoured over TCMS because it attains lasting extreme water repellency at a lower concentration that could ensure significant cost savings.

\section{Water to silane ratio}

The water repellent samples to which both water and silanes were added produced marginal gains of water repellency. Figure 5 shows that the CAs increased from $137^{\circ}$ to $140^{\circ}$ and $126^{\circ}$ to $131^{\circ}$ at a water to silane ratio of 2.97 and 1.76 for OTS and TCMS, respectively. The 2.97 and 1.76 ratios are equivalent to the water content of LBS at room temperature $\left(25^{\circ} \mathrm{C}\right)$. This response was not seen with DCDMS, with the CAs increasing continuously with the water content until $134^{\circ}$. This distinct behaviour suggests that DCDMS is less sensitive to the presence of pore water and thus simpler to handle during preparation.

The differences in higher water to silane ratio for OTS as compared with TCMS can be justified by considering the molecular structure of the chemical compounds. Steps in the silanisation process include primarily a reaction between water in liquid and vapour form to produce a silane polymer. The reaction proceeds by stripping chlorine atoms from the chemical compounds. Since OTS has a larger number of chlorine atoms as compared with TCMS, more water is needed to substitute the chlorine atoms, thus explaining the higher water to silane ratio.

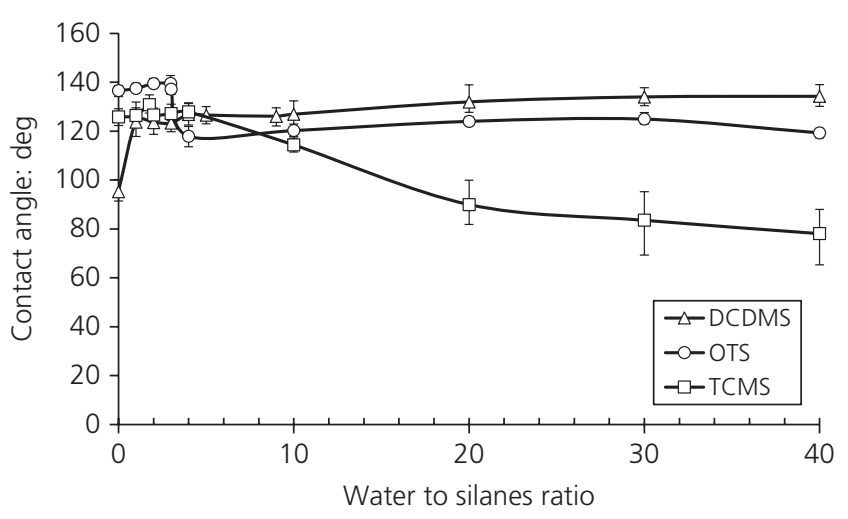

Fig. 5. CAs at increasing water to silane ratios for TMCS, DCDMS and OTS on LBS

\section{Criteria to select the silane concentration}

Selecting the maximum CA or maximum WDPT may not be necessary or cost effective to impart soil water repellency. To select the silane concentration, a combination of magnitude of water repellency (CAs) and its stability (WDPT) is suggested. In Fig. 3, the final few degrees, in the range of $3-8^{\circ}$ from 0.001 to $0 \cdot 004 \%$ by sand mass of silane, require more silane to induce water repellency than for concentrations up to $0.001 \%$. For OTS, at $0.001 \%$ the CAs are $\gg 90^{\circ}$ and the WDPT rating is already at its maximum (class 10). Therefore, beyond $0.001 \%$, any increase in the concentration will not deliver any major increase in water repellency. Thus, the silane concentration to induce high and stable water repellency for LBS is selected as $0.001 \%$ by sand mass of OTS, $0.00175 \%$ of DCDMS and $0.004 \%$ of TMCS. This corresponds to extreme water repellency (class 10) for the three silanes and CAs of $131^{\circ}$ for TMCS, $123^{\circ}$ for DCDMS and $130^{\circ}$ for OTS. Note that while the water repellent behaviour is not expected to change beyond the three mentioned CAs, changes are possible on the mechanical behaviour. In addition to the presence of meniscus water that is known to influence the mechanics of water repellent soils (Kim et al., 2013), at increasing concentrations the coatings will thicken or excess polymer will form in the pores and this may also modify the particle-to-particle friction characteristics.

\section{CONCLUSIONS}

DCDMS, OTS and TMCS were systematically tested for their maximum water repellency (SDM), stability (WDPT) and conditions to enhance their water repellency by way of the initial water content. The three silanes were found to induce high and stable water repellency in an industrial sand albeit with small differences in the maximum CAs and time stability. Selecting the concentration of DCDMS, OTS and TMCS to achieve CAs $\gg 90^{\circ}$ and WDPT class of 10 allows for cost reduction and material saving. Using this criteria, OTS requires the least amount of silane $(0.001 \%$ by sand mass), followed by DCDMS $(0.00175 \%)$ and TMCS $(0 \cdot 004 \%)$. Silanisation was sensitive to the presence of residual water, with the CAs increasing in the range of $\sim 3^{\circ}$ for a water to silane ratio of $\sim 2$.

\section{ACKNOWLEDGEMENTS}

Financial support provided by the General Research Fund, Research Grants Council, Hong Kong (17205915) is acknowledged. Mr Yunesh Saulick (HKU) and Mr Shuang Zheng (HKU) provided comments on the paper. 


\section{REFERENCES}

Bachmann, J., Woche, S. K., Goebel, M. O., Kirkham, M. B. \& Horton, R. (2003). Extended methodology for determining wetting properties of porous media. Water Resour. Res. 39, No. $12,1353-1366$

Bond, R. D. \& Harris, J. R. (1964). The influence of the microflora on the physical properties of soils. I. Effects associated with filamentous algae and fungi. Aust. J. Soil Res. 2, 111-122.

Byun, Y. H., Tran, M. K., Yun, T. S. \& Lee, J. S. (2012). Strength and stiffness characteristics of unsaturated hydrophobic granular media. ASTM Geotech. Test. J. 35, No. 1, 1-8.

DeBano, L. F. 1981. Water repellent soils: a state-of-the-art, Gen. Tech. Rep. PSW-46. Berkeley, CA, USA: U.S. Department of Agriculture, Forest Service, Pacific Southwest Forest and Range Experiment Station.

Dekker, L. \& Ritsema, C. (1994). How water moves in a water repellent sandy soil: 1 . Potential and actual water repellency. Water Resour. Res. 30, No. 9, 2507-2517.

Doerr, S., Shakesby, R., Dekker, L. \& Ritsema, C. (2006). Occurrence, prediction and hydrological effects of water repellency amongst major soil and land-use types in a humid temperate climate. Eur. J. Soil Sci. Eur. J. Soil Sci. 57, No. 5, 741-754.

Gao, L. \& McCarthy, T. (2006). A perfectly hydrophobic surface (theta(A)/theta(B) $=180$ degrees $/ 180$ degrees). J. Am. Chem. Soc. 128, No. 28, 9052-9053.

Gilmour, D. (1968). Water repellence of soils related to surface dryness. Aust. Forestry 32, No. 3, 143-148.

Jamison, V. (1946). The penetration of irrigation and rain water into sandy soil of Central Florida. Soil Sci. Soc. Am. J. 10, No. C, 25-29.

Ju, Z., Ren, T. \& Horton, R. (2008). Influences of dichlorodimethylsilane treatment on soil hydrophobicity, thermal conductivity, and electrical conductivity. Soil Sci. 173, No. 7, 425-432.

Kim, D. H., Kim, B. S., Yun, T. S., Kato, S. \& Park, S. W. (2013). Characterization of geomechanical and hydraulic properties of non-wettable sands. Proceedings of 18th international conference on soil mechanics and geotechnical engineering, pp. 361-364. Paris, France: CRC Press/Balkema.

Lamparter, A., Bachmann, J., Göbel, M. O. \& Woche, S. K. (2009). Carbon mineralization in soil: impact of wetting-drying, aggregation and water repellency. Geoderma 150, No. 3-4, 324-333.

Mahltig, B. \& Bottcher, H. (2003). Modified silica sol coatings for water-repellent textiles. J. Sol-Gel Sci. Technol. 27, No. 1, $43-52$.

Ng, S. H. \& Lourenço, S. D. N. (2016). Conditions to induce water repellency in soils with dimethyldichlorosilane. Géotechnique, 66, No. 5, 441-444, http://dx.doi.org/10.1680/jgeot.15.T.025.

Pagliaro, M., Ciriminna, R. \& Palmisano, G. (2009). Silica-based hybrid coatings. J. Mater. Chem. 19, 3116-3126.

Roper, M. (2005). Managing soils to enhance the potential for bioremediation of water repellency. Aust. J. Soil Res. 43, No. 7, 803-810.

Schuyten, H. A., Reid, J. D., Weaver, J. W. \& Frick J. G. Jr (1948). Imparting water-repellency to textiles by chemical methods. A review of the literature. Textile Res. J. 18, No. 7, 396-398.

Tripp, C. \& Hair, M. (1995). Reaction of methylsilanols with hydrated silica surfaces: the hydrolysis of trichloro-, dichloro-, and monochloromethylsilanes and the effects of curing. Langmuir 11, No. 1, 149-155.

Zhou, W., Liu, M., Chen, N. \& Sun, X. (2015). Corrosion properties of sol-gel silica coatings on phosphated carbon steel in sodium chloride solution. J. Sol-Gel Sci. Technol. 76, No. 2, $358-371$. 